\title{
Coupled Approach to Assess Caprock Deformation Caused by CO2 Injection
}

\author{
C. Li $^{1}$, P.E., P. Barès ${ }^{2}$, P.E. and L. Laloui ${ }^{3}$, Ph.D., P.E. \\ ${ }^{1}$ Laboratory of soil mechanics - Chair "Gaz naturel" Petrosvibri, Swiss Federal Institute of \\ Technology, EPFL, Lausanne, Switzerland; chao.li@epfl.ch \\ ${ }^{2}$ Laboratory of soil mechanics - Chair "Gaz naturel" Petrosvibri, Swiss Federal Institute of \\ Technology, EPFL, Lausanne, Switzerland; paul.bares@epfl.ch \\ ${ }^{3}$ Laboratory of soil mechanics - Chair "Gaz naturel" Petrosvibri, Swiss Federal Institute of \\ Technology, EPFL, Lausanne, Switzerland; lyesse.laloui@epfl.ch
}

\begin{abstract}
This study focuses on a specific problem related to the caprock deformation induced by the injection of $\mathrm{CO} 2$ at depth. The adopted methodology includes the development of a mathematical model that incorporates the deformable behaviour of storage media and the flow of two immiscible fluids (CO2 and water) within the aquifers while the surface rock or caprock layer is modelled as a thin plate. Governing equations are solved for the axisymmetric flexural deflection due to a constant rate of injection of CO2. The results show that this semi-analytical solution is capable of capturing the pressure build-up during the very early stage of injection, resulting in a high rate of surface uplift. The calculation time required using the semianalytical solution is very short; it can be employed as a preliminary design tool for risk assessment using parameters such as the injection rate, porosity, rock properties and geological structures. This semi-analytical solution provides a convenient way to estimate the influence of high injection rates of $\mathrm{CO} 2$ on the caprock deformation. The methodology in this development can easily incorporate other pressure distributions; thus advances in hydrology researches can also benefit this approach.
\end{abstract}

\section{INTRODUCTION}

At In Salah CO2 storage site in central Algeria, CO2 has been injected into a deep seated aquifer since 2004 and surface heave has been detected at a rate of up to $7 \mathrm{~mm} /$ year around each of the three injection wells (Onuma and Ohkawa 2009; Vasco et al. 2008). High rates (>1Mt/year) of injection of CO2 into an aquifer could result in an abrupt fluid pressure build-up within the injection area (Rohmer and Seyedi 2010). This increase in fluid pressure leads to deformation of the sealing caprock. Induced strain propagates to the surface (Ringrose et al. 2013), resulting in 
surface uplift. Employing a hydromechanical coupling technique can help estimate the caprock deformation more accurately.

In such context of underground $\mathrm{CO} 2$ injection, this paper assesses the caprock deformation by deriving a semi-analytical solution, which takes into account a realistic evolution of overpressures as well as the advancing front of CO2 in an initially saturated reservoir. In the first part of the work, a mathematical analysis of the pressurization-induced displacement is given. This is followed by the incorporation of the real distribution of overpressures. Several numerical simulations using the semi-analytical analysis are performed.

\section{METHODOLOGY}

The proposed axisymmetric system consists of an overburden region and a storage unit with a primary caprock in between. CO2 is injected into a m-metre-thick injection zone within a storage unit with a distance $l$ to the primary caprock (Fig. 1). Injection of fluids at a constant rate through a vertical injection well causes radial pressurization in the injection zone, the so-called disc-shaped pressurized zone. The approach assumes that (i) the caprock is oriented horizontally and embedded between an overburden region and a storage region, (ii) the caprock layer is considered as a thin plate and (iii) it behaves elastically. The assumption of a thin plate applied here is justified by its thickness in relation to the dimension (radius) of the pressurized zone (Selvadurai 2000). Both overburden and storage regions are modelled as half-space regions and an isotropic elastic model is applied to these regions.

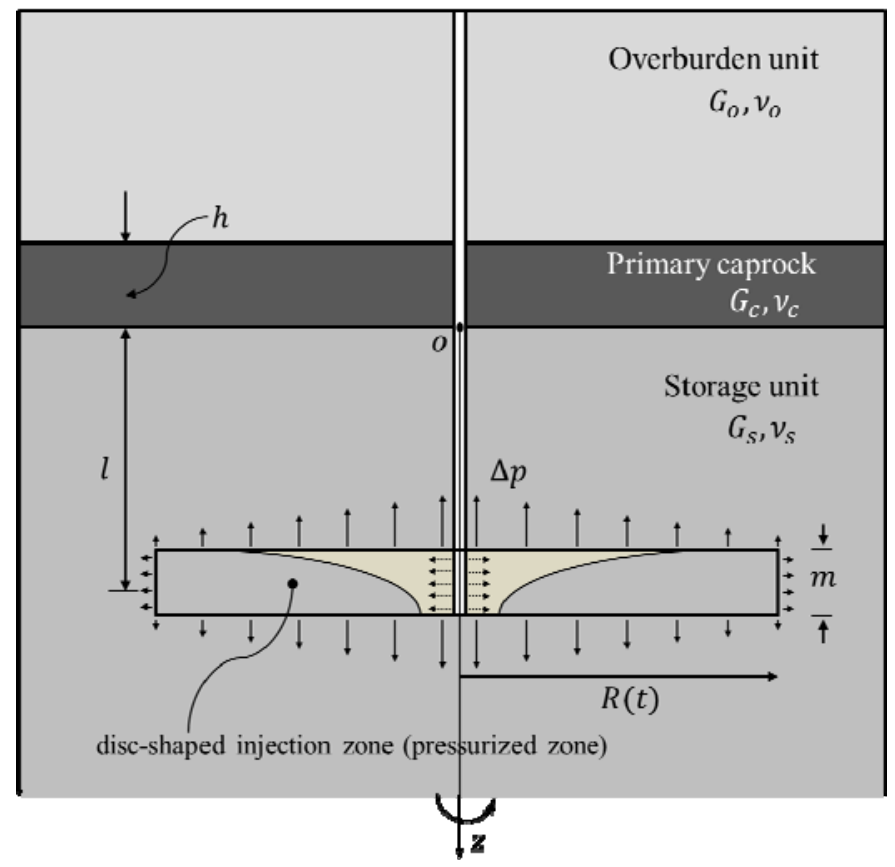

Fig. 1. The idealized configuration of an embedded caprock layer. The injection well corresponds to the axis of symmetry (z-axis). 
The embedded caprock layer exhibits flexural behaviour that is governed by the Germain-Poisson-Kirchhoff thin plate theory (Selvadurai 2000). The governing equation is written in polar coordinates with the Laplace operator $\tilde{\nabla}^{2}=\frac{d^{2}}{d r^{2}}+\frac{1}{r} \frac{d}{d r}$ :

$$
D \tilde{\nabla}^{2} \tilde{\nabla}^{2} w(r)+q^{(s)}(r)-q^{(o)}(r)=0
$$

where the deflection $w(r)$ is constrained by contact stresses $q^{(s)}(r)$ and $q^{(o)}(r)$, which are applied on the contact faces between the caprock and respective regions. The flexural rigidity of the embedded caprock layer is expressed by $D\left(=G_{c} h^{3} / 6\left(1-v_{c}\right)\right)$ with the thickness $h$ of the caprock layer, shear modulus $G_{c}$ and Poisson's ratio of the caprock $v_{c}$. The pressurization of intensity $\Delta p\left[\mathrm{~Pa} / \mathrm{m}^{3}\right]$ is within a disc-shaped pressurized region with a thickness $m$ located at a distance $l$ from the interface between the caprock and the storage region as shown in Fig. 1.

The interactions between the caprock and the adjacent regions are induced by the pressurization that can be considered as an injection pressure over the hydrostatic pressure presented in the storage region. Its induced deflection can be written according to Segall et al. (1994):

$$
u_{z}^{(s) p}(r, 0)=\frac{\alpha_{s}}{G_{s}} \int_{0}^{\infty} \int_{0}^{\infty} \Delta p(\rho) \cdot g_{z}(r, z=0 ; \rho, d) \mathrm{d} \rho \mathrm{d} d
$$

where $\alpha_{s}$ is the biot coefficient, $G_{S}$ is the shear modulus of the storage unit and

$$
g_{z}(r, z=0 ; \rho, d)=-\left(1-2 v_{s}\right) \rho \int_{0}^{\infty} \xi J_{0}(\xi r) J_{0}(\xi \rho) e^{-\xi d} \mathrm{~d} \xi
$$

is the Green's function, which corresponds to a ring of dilatation at radius $\rho \in[0, \infty]$ and depth $d \in[l-m / 2, l+m / 2] . J_{0}$ denotes the Bessel function of first kind of zeroth order and $v_{s}$ is the Poisson ratio of storage unit.

With appropriate kinematic constrains (Selvadurai 2009), one can deduce the deflection of the caprock layer induced by an arbitrary radial pressurization after the solving Eq.(1) using Hankel transform:

$$
w(r)=\frac{\Omega m}{h^{2}} \int_{0}^{\infty} \frac{\xi}{1+\Phi \xi^{3}} \overline{\Delta p}\left(\frac{\xi}{h}\right) e^{-\frac{\xi l}{h}} J_{0}\left(\frac{\xi r}{h}\right) d \xi
$$

where $\Omega$ and $\Phi$ are constants dependant on the properties of the medium (with shear modulus $G_{o}$ and Poisson's ratio $v_{o}$ of overburden unit):

$$
\begin{gathered}
\Omega=\frac{\alpha_{s}\left(1-v_{s}\right)\left(1-2 v_{s}\right)\left(3-4 v_{o}\right)}{G_{s}\left(1-v_{s}\right)\left(3-4 v_{o}\right)+G_{o}\left(1-v_{o}\right)\left(3-4 v_{s}\right)} \\
\Phi=\frac{\left(3-4 v_{s}\right)\left(3-4 v_{o}\right) G_{c}}{24\left(1-v_{c}\right)\left[G_{s}\left(1-v_{s}\right)\left(3-4 v_{o}\right)+G_{o}\left(1-v_{o}\right)\left(3-4 v_{s}\right)\right]}
\end{gathered}
$$

To find the deflection $\mathrm{w}(\mathrm{r})$ according to Eq.(4), the overpressure distribution $\overline{\Delta p}$ must be incorporated. It can be derived from vertically averaged overpressure 
expressions (deduced by Vilarrasa et al. (2010)) from two analytical solutions proposed by Nordbotten et al. (2005), denoted by NB and Dentz and Tartakovsky (2009), denoted by DZ. Both solutions consider that an abrupt interface separates the two fluids, which are assumed to be immiscible (Bear 1972). Introducing both solutions into Eq.(4), we can obtain the CO2 injection-induced caprock deflection, taking into consideration the real distribution of overpressure in the aquifer that has a moving interface associated with the hydrodynamic displacement of immiscible fluids.

\section{NUMERICAL APOPLICATION}

Here we considered an example of a 100 m thick caprock layer which is $1 \mathrm{~km}$ underground. Through a vertical well with a radius $r_{w}=0.15 \mathrm{~m}, \mathrm{CO} 2$ is injected at a constant rate of $100 \mathrm{~kg} / \mathrm{s}$ into an $m=100 \mathrm{~m}$ thick aquifer which located below the caprock. Material parameters are listed in the Table 1.

Table 1. Parameter values used in numerical experiments.

\begin{tabular}{|c|c|c|c|c|c|}
\hline Parameter & Symbol & Unit & $\begin{array}{c}\text { Overburden } \\
\text { unit }\end{array}$ & $\begin{array}{c}\text { Storage } \\
\text { unit }\end{array}$ & $\begin{array}{c}\text { Caprock } \\
\text { layer }\end{array}$ \\
\hline Shear modulus & $G o, G s, G c$ & $\mathrm{GPa}$ & 1 & 10 & 5 \\
\hline Poisson's ratio & $v_{o}, v_{s}, v_{c}$ & - & 0.25 & 0.25 & 0.25 \\
\hline $\begin{array}{l}\text { Porosity in the injection } \\
\text { zone }\end{array}$ & $\phi$ & - & & 0.15 & - \\
\hline $\begin{array}{l}\text { Permeability in the injection } \\
\text { zone }\end{array}$ & $\mathrm{k}$ & $\mathrm{m}^{2}$ & & $1.0 \mathrm{e}-13$ & - \\
\hline Thickness of the caprock & $m$ & $\mathrm{~m}$ & & 100 & \\
\hline $\begin{array}{l}\text { Distance from the caprock } \\
\text { to the middle of the } \\
\text { injection zone }\end{array}$ & $l$ & $\mathrm{~m}$ & & 50 & \\
\hline Well radius & $r_{w}$ & $\mathrm{~m}$ & & 0.15 & \\
\hline Injection rate & $Q_{m}$ & $\mathrm{~kg} / \mathrm{s}$ & & 100 & \\
\hline
\end{tabular}

The spatial distribution of overpressure is displayed in the Fig. 2. As the same as stated in (Vilarrasa et al. 2010), the overpressure decreases with distance logarithmically in the DZ solution while it decreases linearly with the solution of NB over the region where the two fluids coexist. As expected, the overpressure calculated using the DZ solution is higher than the one using NB. The pressurization-induced deflection has the same trend as the overpressure (Fig. 3). The curvature of the deflected shape is smoother in the case of NB around the injection well than that with the solution of DZ, which will further influence the stress development. 


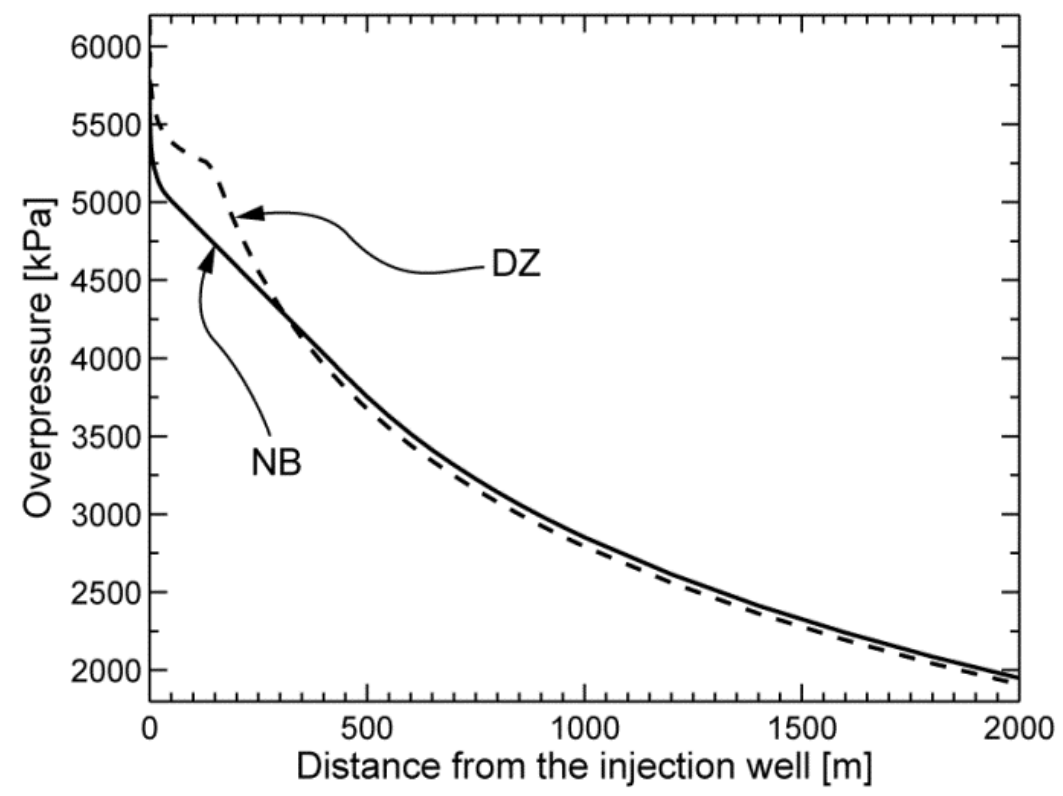

Fig. 2. Spatial distribution of vertically averaged overpressure after 100 days of injection the reference parameters.

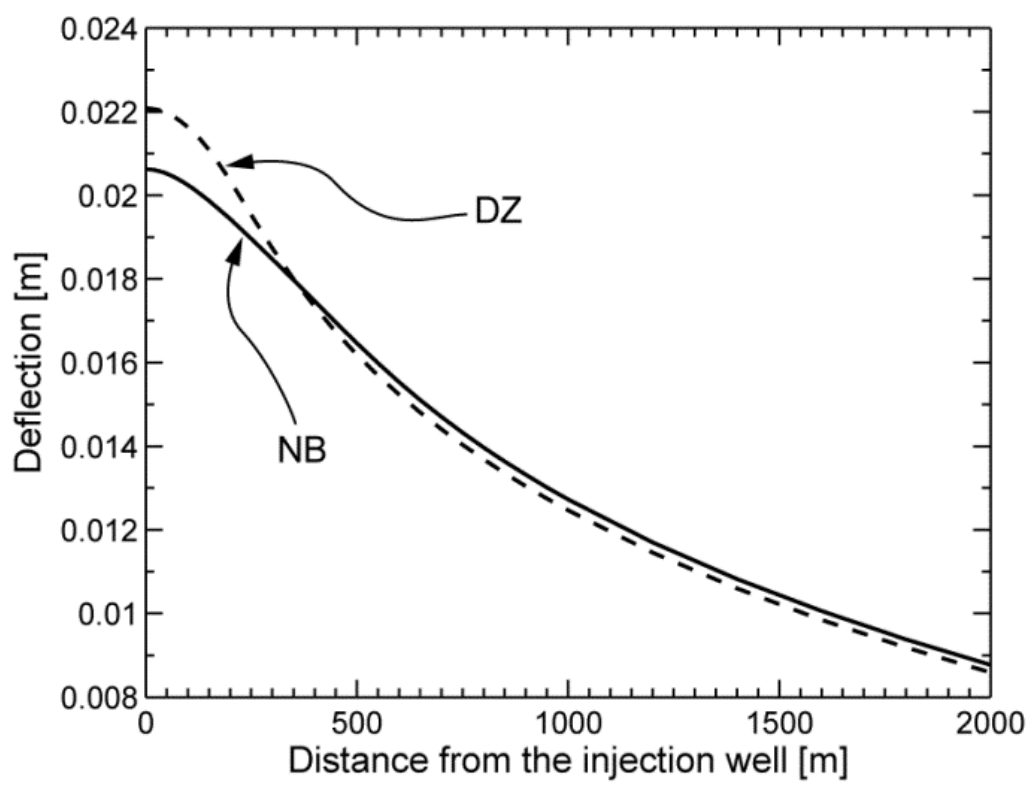

Fig. 3. Spatial distribution of the deflection of the caprock after 100 days of injection with the reference parameters. 


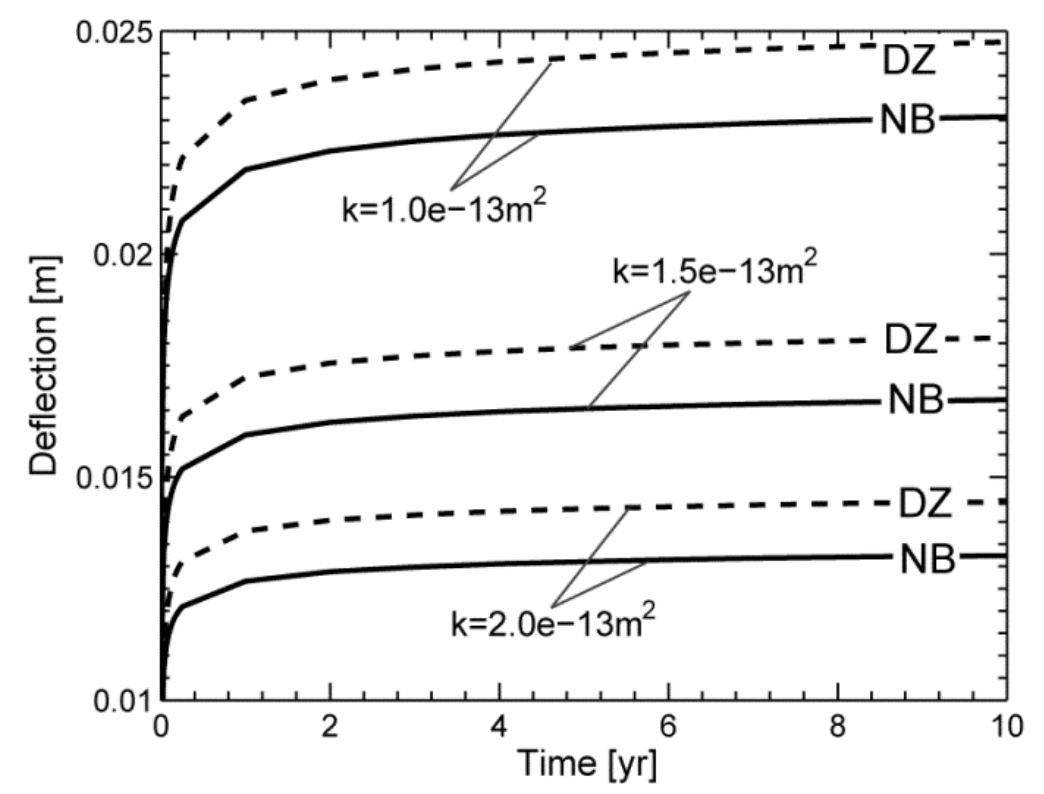

\section{Fig. 4. Deflection at the injection well with time with the variation in permeability.}

Temporal evolution of the caprock deflection is shown in Fig. 4 with various permeabilities. With a constant rate of injection, the fluid pressure increases dramatically at the very beginning of the injection period. As a consequence of the elastic model, the deflection reflects the effect of overpressure and shows the same behavior. The deflection increases gradually after one year of injection and reaches a maximum. The deflection is almost proportional to the inverse of the permeability. Thus the permeability can be considered as an important factor to limit the overpressure build-up and subsequent deflections.

\section{CONCLUSIONS}

This paper presents a semi-analytical approach to estimate the caprock deflection due to $\mathrm{CO} 2$ injection. The model examines the interaction between a primary caprock and adjacent regions with elastic material properties, which is induced by the pressurization within the injection zone. Using the embedded plate approach, the primary caprock is modelled as a thin-plate layer and adjacent regions are modelled as semi-infinite half-space regions. For the fluid part, two analytical solutions have been introduced into this approach. Benefit of employing these two solutions is that a moving front of immiscible fluids and a more realistic fluid pressure distribution can be taken into account. Several numerical experiments have been undertaken to illustrate the influence of factors such as geometry, overpressure magnitude and material properties on the caprock deflection. 


\section{ACKNOWLEDGMENTS}

The authors gratefully acknowledge Petrosvibri S.A. for funding of the Chair "Gaz Naturel” and supporting this research.

\section{REFERENCES}

Bear, J., (1972). Dynamics of fluids in porous media. Elsevier, New York.

Dentz, M. and Tartakovsky, D.M., (2009). "Abrupt-interface solution for carbon dioxide injection into porous media." Transport in Porous Media 79, 15-27

Nordbotten, J.M., Celia, M.A. and Bachu, S., (2005). "Injection and storage of CO2 in deep saline aquifers: Analytical solution for CO2 plume evolution during injection." Transport in Porous Media 58, 339-360

Onuma, T. and Ohkawa, S., (2009). "Detection of surface deformation related with CO2 injection by DInSAR at In Salah, Algeria." Energy Procedia 1, 2177-2184

Ringrose, P.S., Mathieson, A.S., Wright, I.W., Selama, F., Hansen, O., Bissell, R., Saoula, N. and Midgley, J., (2013). "The In Salah CO2 storage project: lessons learned and knowledge transfer(in press.)." Energy Procedia

Rohmer, J. and Seyedi, D.M., (2010). "Coupled Large Scale Hydromechanical Modelling for Caprock Failure Risk Assessment of CO2Storage in Deep Saline Aquifers." Oil \& Gas Science and Technology - Revue de l'Institut Français du Pétrole 65, 503-517, doi:10.2516/ogst/2009049.

Segall, P., Grasso, J.-R. and Mossop, A., (1994). "Poroelastic stressing and induced seismicity near the Lacq gas field, southwestern France." Journal of Geophysical Research: Solid Earth 99, 15423-15438, doi:10.1029/94JB00989.

Selvadurai, A.P.S., (2000). Partial Differential Equations in Mechanics 2: The Biharmonic Equation, Poisson's Equation. Springer.

Selvadurai, A.P.S., (2009). "Heave of a surficial rock layer due to pressures generated by injected fluids." Geophysical Research Letters 36, L14302, doi:10.1029/2009GL038187.

Vasco, D.W., Ferretti, A. and Novali, F., (2008). "Reservoir monitoring and characterization using satellite geodetic data: Interferometric synthetic aperture radar observations from the Krechba field, Algeria." Geophysics 73, WA113WA122

Vilarrasa, V., Bolster, D., Dentz, M., Olivella, S. and Carrera, J., (2010). "Effects of CO2 Compressibility on CO2 Storage in Deep Saline Aquifers." Transport in Porous Media 85, 619-639 